\title{
Morphometry of endoneurial capillaries in diabetic sensory and autonomic neuropathy
}

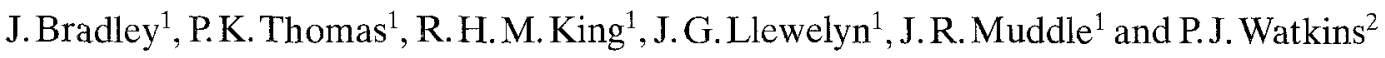 \\ ${ }^{1}$ Department of Neurological Science, Royal Free Hospital School of Medicine, and \\ 2 Diabetic Department, King's College Hospital, London, UK
}

Summary. Nerve biopsies were obtained from 27 patients with diabetic neuropathy. All had a symmetric distal sensory and autonomic neuropathy or a purely sensory neuropathy. Mean age was 39.8 years (range 23-57 years). Two patients had Type 2 (non-insulin-dependent) diabetes mellitus and the remainder Type 1 (insulin-dependent) diabetes. Morphometric observations on endoneurial capillaries were compared with results from organ donor control cases and from patients with type 1 hereditary motor and sensory neuropathy. The area of the lumen of the capillaries did not differ between the three groups. The area occupied by the capillary endothelial cells in transverse section and the number of endothelial cell nuclei were increased both in the patients with diabetic neuropathy and hereditary motor and sensory neuropathy, as was the thickness of the surrounding basal laminal zone. 'Closure' of endoneurial capillaries in diabetic neuropathy, reported in another study, was not confirmed. Capillary density and nearest-neighbour distances were similar in the diabetic and organ donor control cases. Capillary density was reduced in the patients with hereditary motor and sensory neuropathy, this being related to increased fascicular area consequent upon the presence of hypertrophic changes. The presence of thickening of the pericapillary basal laminal zone and endothelial cell hyperplasia both in diabetic and hereditary motor and sensory neuropathy, the latter being a neuropathy in which a vascular basis can be discounted, makes it difficult to use such changes as an argument favouring a vascular cause for diabetic neuropathy. There were differences in the basal laminal zone between the diabetic and hereditary motor and sensory neuropathy cases suggesting that the reduplicated basal lamina was more persistent in the diabetic patients.

Key words: Diabetic neuropathy, hereditary motor and sensory neuropathy, sural nerve, endoneurial capillaries, basal lamina.
It is likely that focal neuropathies of acute onset in patients with diabetes mellitus, such as lesions of the third cranial nerve, have a vascular basis, although confirmatory pathological studies are scarce [1]. Older views which had fallen into disfavour that most diabetic neuropathy, including the distal symmetric sensory and autonomic polyneuropathies, is due to vascular disease [2-4], have recently been revived. This has partly resulted from observations on experimental diabetes in animals $[5,6]$, and partly from observations in man [7-16].

Most of these human studies have been undertaken on older patients. The mean age in the autopsied series reported by Johnson et al. [10] was 64 years. In the nerve biopsy study reported by Dyck et al. [9] it was 52 years in men with insulin-dependent diabetes mellitus (only 3 women were included), and 56 years for men and 55 years for women with non-insulin-dependent diabetes. In this study we have therefore examined sural nerve biopsies from a series of 27 younger patients with diabetic neuropathy with a mean age of 39.8 years. Morphometric observations on endoneurial capillaries were compared with observations made on sural nerve biopsies from organ donor control cases and from patients with type 1 hereditary motor and sensory neuropathy (HMSN), a subtype of peroneal muscular atrophy and a condition in which a vascular basis is not entertained.

\section{Subjects and methods}

All 27 diabetic patients (13 male, 14 female; mean age 39.8 years, range 23-57 years) had clinical and electrophysiological evidence of a distal symmetric predominantly sensory polyneuropathy. None had evidence of focal cranial, thoracoabdominal or limb neuropathy. In 17 patients there was significant autonomic dysfunction, either on clinical assessment (symptoms of postural hypotension, diabetic diarrhoea and gustatory sweating) or on formal testing (a drop of $30 \mathrm{~mm} \mathrm{Hg}$ or more in systolic blood pressure on standing, and heart rate variation on deep breathing of less than 10 beats $/ \mathrm{min}$ ). It is recognized that some of those without autonomic symptoms may have had abnormal functional tests had they been performed. The clinical and biochemical data, at or near the time of nerve biopsy, are given in Table 1. Twenty-five patients had insulin-dependent diabetes and all were receiving highly purified porcine or bovine insulin; two patients had non-insulin-dependent diabetes.

Absent dorsalis pedis pulses were documented in four patients (Cases 14, 18, 21, 23; Table 1); none had symptoms of claudication. 


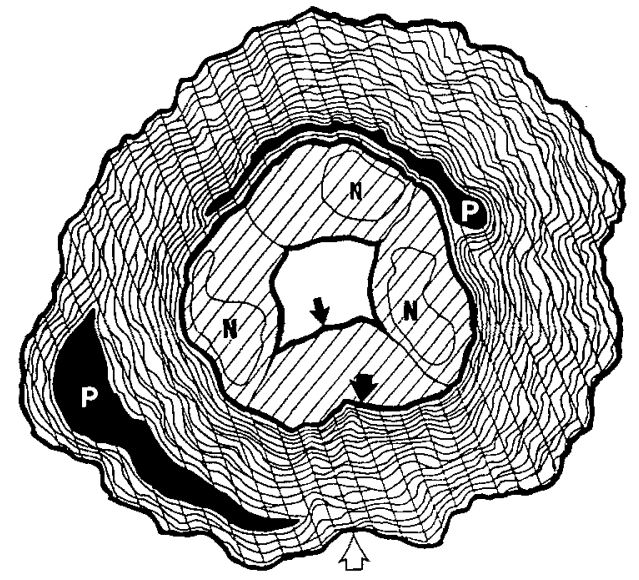

Fig. 1. Diagram of transverse section through an endoneurial capillary to illustrate the measurements obtained. $\mathrm{N}=$ endothelial cell nuclei; $\mathrm{P}=$ pericyte processes. Small black arrow indicates the perimeter of the lumen, the large black arrow the perimeter of the endothelial cell layer and the white arrow, the perimeter of the basal laminal zone

Patient 16 had absent distal pulses in both legs and claudication and required a below knee amputation on one side. Five patients (patients $8,9,21,23,24)$ had neuropathic foot ulceration and two of these (patients 21,23 ) underwent below knee amputation because of persistent infection. One patient (patient 13) had neuropathic arthropathy at the ankle.

Sural nerve fascicular biopsies were taken from a site posterior to the lateral malleolus under local anaesthesia in 23 patients, with in- formed consent and with the approval of the Ethics Committee at King's College Hospital. Sural nerves were removed immediately following amputation in three patients. Radial nerve biopsy was performed in patient 18 .

Total sural nerve biopsies were obtained from the same site in nine organ donor cases (five male, four female, mean age 44.7 years; range $28-55$ years) at the time of organ donation with the consent of the next of kin and the approval of the Ethics Committee at the Royal Free Hospital. In all except one instance, the nerve biopsies were taken during life before ventilatory arrest. In one case, the sural nerve was removed within 45 min of circulatory occlusion. As the results in this subject were well within the normal range obtained for the others, it was considered justifiable to include them. No patient was known to have neuropathy and none had disorders in which peripheral neuropathy may occur. Sural nerve fascicular biopsies, again from the same retromalleolar site, previously obtained from nine patients (six male, three female; mean age 32.7 years, range 1157 years) with type $1 \mathrm{HMSN}$ were also studied. The criteria for diagnosis were those of Harding and Thomas [17]. In most, inheritance was of autosomal dominant pattern. The HMSN cases were chosen as they represented a group of patients with an appropriate age range who had a defined disorder for which a vascular pathogenesis has never been discovered.

Portions of the biopsy specimens were fixed in $3 \%$ glutaraldehyde in piperazine-N-N'-bis(2-ethane sulphonic acid) (PIPES) buffer [18] with $2 \%$ sucrose. After postfixation in $1 \%$ osmium tetroxide in PIPES buffer containing $1.5 \%$ potassium ferricyanide, the specimens were dehydrated through increasing concentrations of ethanol and embedded in Araldite via 1,2-epoxypropane. Transverse ultrathin sections were cut and stained with uranyl acetate and lead citrate and examined in a JEOL 100CX electron microscope. All endoneurial capillaries in each fascicle were photographed within a magnification range of 1,600 to 6,600 depending on the size of the vessel. All fulfilled

Table 1. Clinical and biochemical data of the diabetic patients

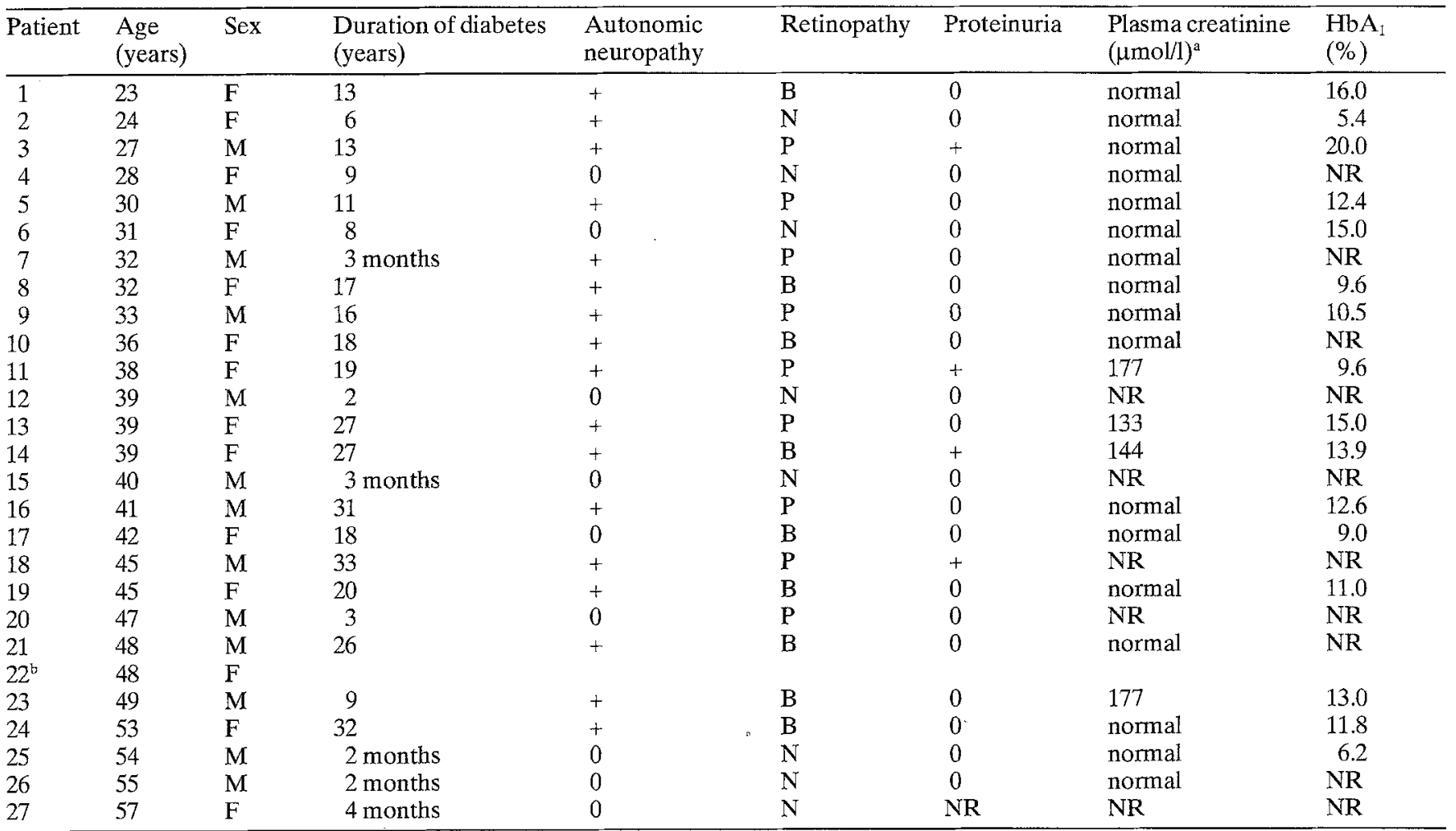

$+=$ present; $0=$ absent

$\mathrm{P}=$ proliferative $; \mathrm{B}=$ background $\mathrm{N}=$ none $; \mathrm{NR}=$ not recorded

a normal range $60-120 \mu \mathrm{mol} / \mathrm{l}$

b clinical data not available 

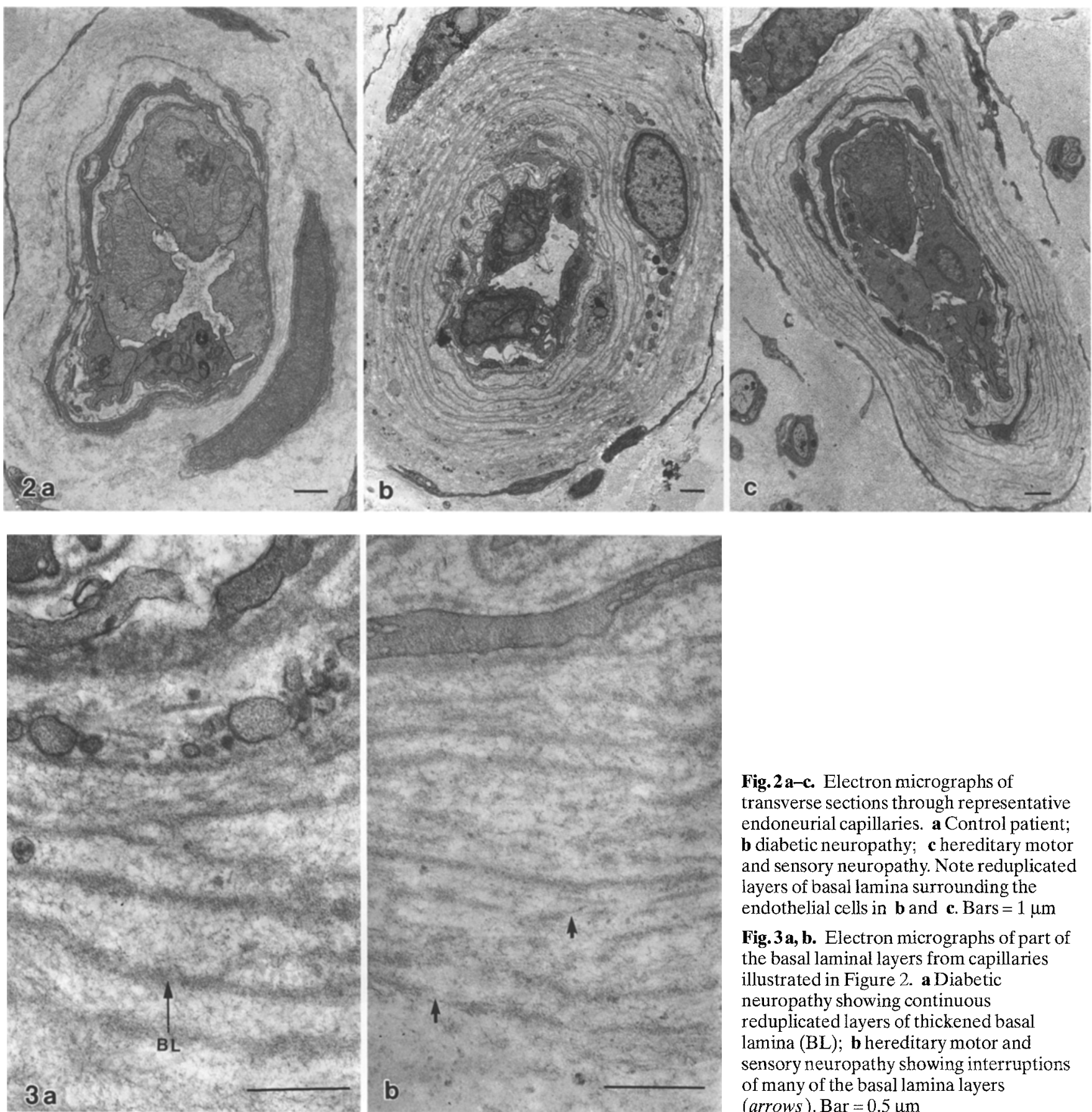

Fig. 2 a-c. Electron micrographs of transverse sections through representative endoneurial capillaries. a Control patient; b diabetic neuropathy; chereditary motor and sensory neuropathy. Note reduplicated layers of basal lamina surrounding the endothelial cells in $\mathbf{b}$ and $\mathbf{c}$. Bars $=1 \mu \mathrm{m}$

Fig. 3 a, b. Electron micrographs of part of the basal laminal layers from capillaries illustrated in Figure 2. a Diabetic neuropathy showing continuous reduplicated layers of thickened basal lamina (BL); b hereditary motor and sensory neuropathy showing interruptions of many of the basal lamina layers (arrows). Bar $=0.5 \mu \mathrm{m}$

the morphological criteria for capillaries given by Bell and Weddell [19]. Measurements were made on photographic enlargements with Kontron MOP Videoplan and IBAS image analysis systems.

Semithin sections from the Araldite-embedded material were stained with thionin and acridine orange [20] for qualitative observations. Another portion of the biopsy specimen was fixed in formolcalcium, paraffin embedded and stained with routine histological stains, again for qualitative observations.

\section{Data collection}

The following parameters were measured on the electron micrographs for each blood vessel: perimeter of the lumen, perimeter of the endothelial cells, perimeter of the basal laminal zone, number of endothelial cell nuclei and number of pericyte processes. The following additional parameters were then derived from these by the image analyser: area of the lumen, area occupied by the endothelial cells and area of the basal laminal zone. A diagram illustrating the measurements obtained is shown in Figure 1. The area of the fascicles was also measured and the number of intrafascicular capillaries counted, from which an estimate of capillary density was derived. Finally, nearest-neighbour distances were recorded for all capillaries.

\section{Statistical analysis}

The results were analysed by the Mann-Whitney $U$ and KruskallWallis tests using median values and interquartile ranges. 

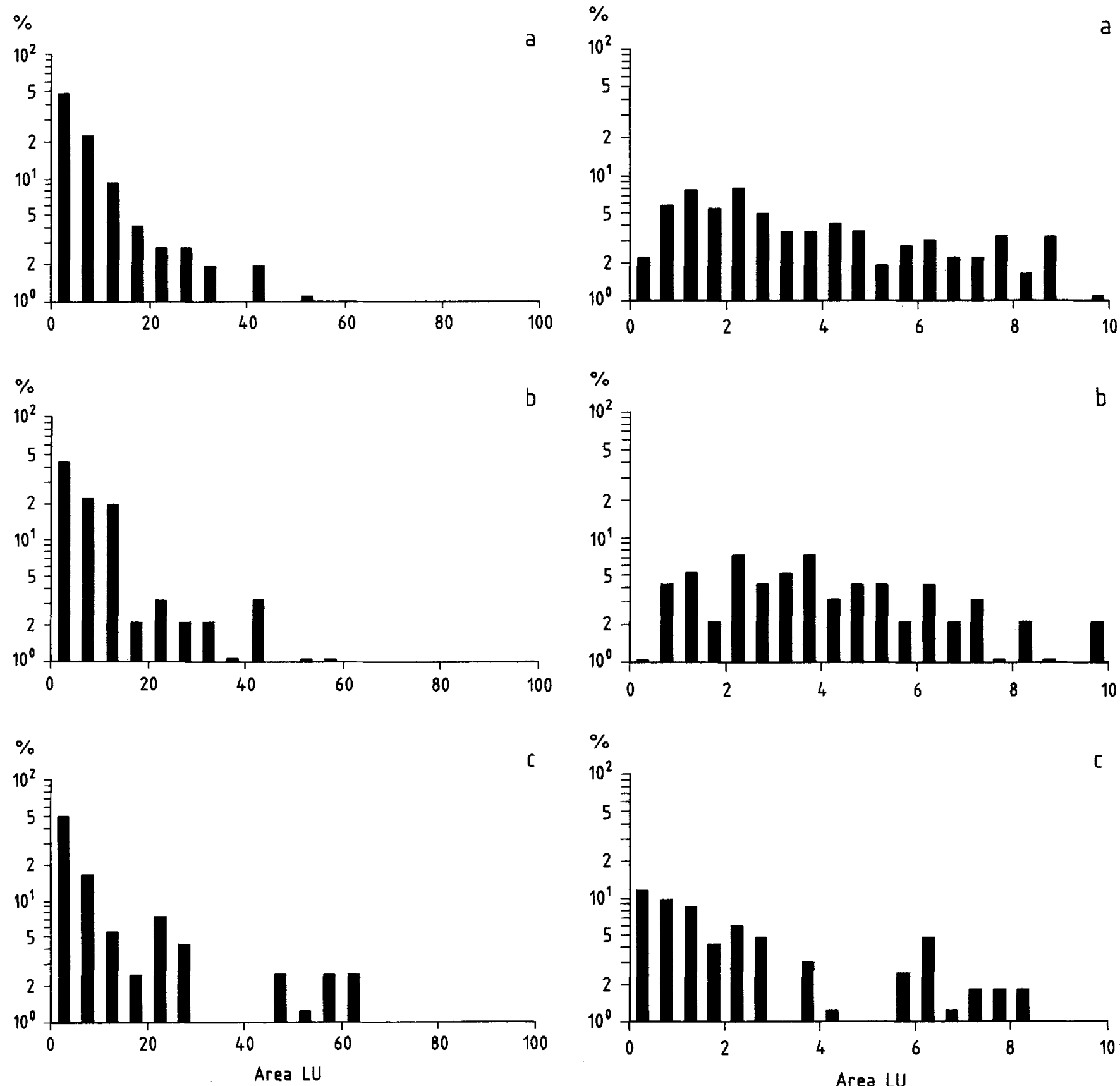

Fig. 4 a-c. Percentage frequency histograms (log scale) for capillary luminal area. a Control; b diabetic neuropathy; chereditary motor and sensory neuropathy

\section{Results}

\section{Qualitative observations}

The endothelial cells of the endoneurial blood vessels from the diabetic patients, donor control subjects and patients with type 1 HMSN were surrounded by a continuous layer of basal lamina external to which were additional layers of basal lamina interspersed with collagen fibrils. Pericytes were also present, defined as cells that partially encircle the endothelial cells, and which are enclosed by basal lamina. Normally the pericytes

are bounded internally by the basal lamina that surrounds the endothelial cells but, with basal laminal reduplication, they may be displaced peripherally. The pericytes showed no recognizable abnormalities in the diabetic or HMSN biopsies. Endoneurial fibroblasts and their processes sometimes partially surrounded the outer limits of the reduplicated basal lamina. Vessels that were enclosed in perineurial ensheathments were excluded. The endoneurial vessels consistently ran in a longitudinal orientation in the long axis of the fascicles and were therefore sectioned transversely. Fenestrated capillaries were not encountered in any of the

Fig.5a-c. Expansion of percentage frequency histograms (log scale) for values less than $10 \mu^{2}$. a Control; b diabetic neuropathy; chereditary motor and sensory neuropathy 
Table 2. Morphometric analysis of endoneurial capillaries in sural nerve in diabetic neuropathy, organ donor control subjects and hereditary motor and sensory neuropathy (HMSN)

\begin{tabular}{|c|c|c|c|}
\hline & $\begin{array}{l}\text { Diabetic } \\
\text { patients }\end{array}$ & $\begin{array}{l}\text { Control } \\
\text { subjects }\end{array}$ & $\begin{array}{l}\text { HMSN } \\
\text { patients }\end{array}$ \\
\hline No. of cases & 27 & 9 & 9 \\
\hline $\begin{array}{l}\text { Luminal area }\left(\mu \mathrm{m}^{2}\right) \\
\text { median } \\
\text { interquartile range }\end{array}$ & $\begin{array}{l}5.3 \\
2.3-12.2\end{array}$ & $\begin{array}{l}4.9 \\
1.0-21.77\end{array}$ & $\begin{array}{l}6.2 \\
3.1-12.7\end{array}$ \\
\hline $\begin{array}{l}\text { Endothelial cell no. } \\
\text { median } \\
\text { interquartile range }\end{array}$ & $\begin{array}{l}2 \\
1-2\end{array}$ & $\begin{array}{l}1 \\
1-2\end{array}$ & $\begin{array}{l}2 \\
1-3\end{array}$ \\
\hline $\begin{array}{l}\text { Basal laminal area }\left(\mu \mathrm{m}^{2}\right) \\
\text { median } \\
\text { interquartile range }\end{array}$ & $\begin{array}{l}172.7 \\
110.2-267.6\end{array}$ & $\begin{array}{l}67.6 \\
43.0-102.6\end{array}$ & $\begin{array}{l}152.8 \\
108.0-249.0\end{array}$ \\
\hline $\begin{array}{l}\text { No. of pericyte processes } \\
\text { median } \\
\text { interquartile range }\end{array}$ & $\begin{array}{l}3 \\
2-5\end{array}$ & $\begin{array}{l}3 \\
2-3\end{array}$ & $\begin{array}{l}2 \\
2-3\end{array}$ \\
\hline $\begin{array}{l}\text { Fascicular area }\left(\mu \mathrm{m}^{2}\right) \\
\text { median } \\
\text { interquartile range }\end{array}$ & $\begin{array}{l}77,110 \\
39,590-11,000\end{array}$ & $\begin{array}{l}66,490 \\
30,680-102,200\end{array}$ & $\begin{array}{l}112,100 \\
76,030-230,500\end{array}$ \\
\hline $\begin{array}{l}\text { No. of capillaries per fascicle } \\
\text { median } \\
\text { interquartile range }\end{array}$ & $\begin{array}{l}4.5 \\
3-8\end{array}$ & $\begin{array}{l}4 \\
2-7\end{array}$ & $\begin{array}{l}5 \\
3-8\end{array}$ \\
\hline $\begin{array}{l}\text { Endoneurial area per capillary }\left(\mu \mathrm{m}^{2}\right) \\
\text { median } \\
\text { interquartile range }\end{array}$ & $\begin{array}{l}14,850 \\
11,460-22,230\end{array}$ & $\begin{array}{l}15,270 \\
11,230-20,460\end{array}$ & $\begin{array}{l}25,630 \\
19,010-28,820\end{array}$ \\
\hline
\end{tabular}

three groups of cases. Observations on semithin Araldite-embedded sections and paraffin-embedded sections showed no evidence of vascular occlusion by platelets and fibrin and no inflammatory infiltrates related to vessel walls or in the endoneurium, perineurium or epineurium. Hyperplasia of endothelial cells was evident in some capillaries both in the diabetic and HMSN biopsies. This is examined quantitatively in the next section.

Electron micrographs of representative vessels from the diabetic, donor control and HMSN cases are shown in Figures $2 \mathrm{a}-\mathrm{c}$. As will be shown quantitatively in the next section, the thickness of the pericapillary basal laminal zone was increased both in the diabetic and HMSN patients as compared with donor control subjects. The inner part of this zone contained identifiable layers of reduplicated basal lamina; the outer part was composed of material with a more amorphous appearance. The layers of basal lamina in the diabetic patients differed from those in the HMSN cases in that they tended to be continuous and slightly thicker, whereas in the HMSN cases the layers were often interrupted and broken up into irregular lengths (Fig.3a, b).

\section{Quantitative observations}

The results obtained for the three groups of cases are given in Table 2 and Figures 4 and 5.

Luminal area. The median value for the area of the lumen in the diabetic patients was $5.3 \mu \mathrm{m}^{2}$. This was slightly greater than that for the donor control cases in whom it was $4.9 \mu \mathrm{m}^{2}$ and slightly less than that for the HMSN cases $\left(6.2 \mu \mathrm{m}^{2}\right)$. These differences were not statistically significant. The proportion of capillaries with the smallest luminal area was not higher in the diabetic patients (Fig. 5). Totally occluded vessels with obliteration of the lumen were not encountered.

Endothelial cells and pericytes. The median area occupied by the endothelial cells in the diabetic cases in transverse section was $31.7 \mu \mathrm{m}^{2}$. This was significantly greater $(p<0.01)$ than that for the donor control subjects in whom it was $24.8 \mu \mathrm{m}^{2}$. Endothelial cell area in the HMSN cases, which was $43.5 \mu \mathrm{m}^{2}$, was significantly greater than that for both the donor control and diabetic patients $(p<0.001)$. The median number of endothelial cell nuclei in trans- 
verse section was identical in the diabetic and HMSN patients and significantly greater than in the organ donor control subjects $(p<0.01)$. If the numbers of nuclei are corrected for the length of the perimeter of the capillaries, the median numbers in the diabetic and HMSN nerves are again both significantly greater than the median number for the control nerves $(p<0.05)$ and that for the diabetic nerves is greater than that for HMSN $(p<0.05)$.

The median number of pericyte processes in transverse section was identical in the diabetic and organ donor patients but the interquartile range was significantly greater in the former $(p<0.01)$. The median number of pericyte processes was significantly less in the HMSN patients. These results are the same if corrected for the length of the perimeter of the capillaries.

Basal laminal zone. The median area occupied by the pericapillary basal lamina zone and its median thickness were substantially greater in the diabetic patients, in whom values were $172.7 \mu \mathrm{m}^{2}$ and $4.65 \mu \mathrm{m}$, respectively, than in the organ donor control subjects where they were only $67.6 \mu \mathrm{m}^{2}$ and $2.28 \mu \mathrm{m}$, respectively. These differences were statistically significant $(p<0.01)$. The values were also greater than in the HMSN patients, in whom they were $152.8 \mu \mathrm{m}^{2}$ and $4.08 \mu \mathrm{m}$, but this difference did not reach statistical significance. The value for the HMSN patients was also significantly greater than that for the organ donor control subjects $(p<0.01)$.

Capillary density. Median fascicular area was slightly but not significantly greater in the diabetic patients as compared with the organ donor control subjects. It was considerably and significantly greater in the HMSN patients $(p<0.01)$, this being attributable to the hypertrophic changes. There was no significant difference in the median number of blood vessels between the three groups, but the median endoneurial area per capillary (reciprocal of capillary density) was significantly increased $(p<0.01)$ in the HMSN nerves as compared both with the organ donor control and the diabetic neuropathy cases. There was no difference in the nearest-neighbour intercapillary distance between the nerves of the diabetic neuropathy patients and those of the control subjects, but it was significantly increased in the nerves of the HMSN patients $(p<0.01)$.

\section{Discussion}

The early suggestions that diabetic neuropathy might have a vascular cause made by Pryce [2] and others were based on the frequent concurrence of large vessel atherosclerotic disease and neuropathy. In the later study by Woltman and Wilder [3] that reached the same conclusion, the observation were largely derived from amputated limbs. In such patients, atherosclerotic disease would have been frequent. Moreover, normal structures in nerve (Renaut bodies) were misinterpreted as infarcts. Subsequently Fagerberg [21] drew attention to the presence of small vessel disease with an accumulation of periodic acid-Schiff (PAS)-positive material around the walls of endoneurial vessels. This material was identified by electron microscopy as reduplicated basal lamina [22]. Fagerberg's study was not quantitative and it received criticism as such changes were not observed consistently in the peripheral nerves of patients with diabetic neuropathy $[23,24]$.

In the recent resurgence of support for a vascular basis for diabetic neuropathy, clear evidence for focal lesions in nerve in autopsied cases has been presented by Johnson et al. [10], Sugimura and Dyck [15] and Dyck et al. [8] but, as stated in the Introduction, these cases were elderly and accompanying vascular disease would not have been unexpected. Dyck et al. [9] also reported that myelinated fibre loss in sural nerve biopsies from a large series of patients with diabetic neuropathy was patchy and multifocal. This was taken as supporting a vascular causation. Nevertheless, the result is difficult to interpret as Llewelyn et al. [25] found a similar patchy pattern of fibre loss in sural nerve biopsies from a series of younger patients with diabetic neuropathy and an identical patchy loss in an agematched group of patients with type 1 HMSN (the same cases as in the present study) with a comparable reduction in myelinated fibre density. Patchy loss of fibres in generalized polyneuropathies therefore does not necessarily indicate vascular pathology, although its explanation is not yet clear.

The most striking piece of evidence to support a vascular causation for diabetic neuropathy is the report by Dyck et al. [7] in which, in a series of sural nerve biopsies, the number of 'closed capillaries' was found to be significantly greater than in age-matched control subjects and that the number of such capillaries was correlated with the severity of neuropathy expressed by an 'index of pathology'. This relationship was found both in insulin-dependent and non-insulin-dependent diabetes. The age of the cases in this series was not given. In the present series we have not been able to confirm this relationship as the area of the lumen of the endoneurial capillaries did not differ either from our organ donor control subjects or patients with type 1 HMSN. In a later publication, Yasuda and Dyck [16] found that endoneurial capillary luminal area was significantly greater in diabetic patients without neuropathy than in control subjects although not significantly different between diabetic patients with neuropathy and control subjects. Despite this, more 'closed' capillaries were again found in the patients with diabetic neuropathy. Our own studies have shown no excess of smaller capillary lumina in the patients with diabetic neuropathy. Completely occluded vessels were not observed. Powell et al. [14] reported that luminal diameter did not differ between diabetic patients with histological evidence of neuropathy and control subjects. Malik et al. [12] found that the perimeter of the lumen of endoneurial capillaries was significantly greater both in diabetic patients without neuropathy and in patients with severe neuropathy as compared with organ donor control subjects. Luminal area was not reported. The majority of studies have therefore concluded that the size of the lumen of endoneurial capillaries is not reduced in diabetic neuropathy.

The thickness of the basal lamina zone was expectedly greater in our diabetic patients as compared with age- 
matched control subjects, as has been observed by others $[12,14,26,27]$. It was also significantly increased in the HMSN cases as compared with the organ donor cases. The increase was not as great as in the diabetic patients, although the difference was not statistically significant. The finding of a thickened basal lamina zone, therefore, cannot be assumed necessarily to stand in causal relationship to the neuropathy. It may, in some instances, be secondary to the neuropathy. This possibility is supported by the observations of Behse et al. [27] and Vital et al. [28] who found basal laminal thickening in a range of acquired neuropathies, although it was more frequent in diabetic neuropathy. The explanation for the accumulation of reduplicated basal lamina around endoneurial blood vessels is at present uncertain. It may not be the same in all neuropathies. It presumably implies repeated alterations in the size of these vessels, each alteration leading to the formation of another layer. It could also be secondary to an increased turnover of endothelial cells. A factor in the accumulation of basal laminal material in diabetes may be an abnormal persistence because of resistance to proteolytic degradation. This has been discussed by King et al. [29]. The fact that in the present study the reduplicated capillary basal laminae tended to remain intact in the diabetic patients whereas they became fragmented in the HMSN cases favours this interpretation.

Hyperplasia of the endothelium of endoneurial capillaries, with both an increase in the number of nuclei and an increase in endothelial cell area in transverse section, has been noted in diabetic neuropathy $[14,26]$. This could again imply increased cell turnover. In the present study, the area occupied by the capillary endothelial cells in transverse section was significantly greater in the patients with diabetic neuropathy than in the organ donor control subjects, but this was also true for the HMSN cases. Thus, it is difficult to relate this hyperplasia of the endothelial cells in a causal way to the occurrence of diabetic neuropathy.

The state of epineurial nutrient vessels is clearly of importance in any consideration of a possible ischaemic basis for diabetic neuropathy. Korthals et al. [11] documented thickening of the intima of epineurial arterioles, due primarily to proliferation of endothelial cells, in diabetes, but no correlation was found between the degree of thickening and the severity of neuropathy as assessed by the amount of nerve fibre loss. The epineurial vessels were not examined in the present study.

The conclusion to be derived from the present study is that morphological observations on nerve biopsies from younger patients with diabetic neuropathy have failed to confirm the occurrence of the 'capillary closure' observed by Dyck et al. [7]. Moreover, because the occurrence of thickening of the basal laminal zone and hyperplasia of the capillary endothelial cells in transverse section is also seen in HMSN, a neuropathy not considered to have a vascular basis, such changes cannot be used to establish a vascular basis for diabetic neuropathy.

A further piece of evidence taken to favour a vascular causation for diabetic neuropathy is the finding of reduced intraneural oxygen tension in patients with diabetic neuropathy in comparison with control subjects [13]. This conclusion cannot be accepted unreservedly at present as the control cases (one of whom was diabetic) were appreciably younger in age. Moreover, measurements of tissue oxygen tension in the lower limbs by transcutaneous recordings have failed to demonstrate a reduction in patients with diabetic neuropathy although they revealed a failure for oxygen tension to increase as well on warming as in control subjects [30], suggesting sympathetic denervation. Direct observations on the nail fold vasculature in the toes have shown an increase in capillary blood flow in patients with diabetic neuropathy and no evidence of capillary closure [31]. Further direct measurements on intraneural oxygen tension in patients with diabetic neuropathy are required as the situation in nerve may differ from that in skin. Malik et al. [12] found that morphological abnormalities were greater in endoneurial than in skin capillaries in diabetes.

The clinical features of diabetic sensory and autonomic polyneuropathy do not immediately suggest vascular disease. In neuropathies known to have a vascular cause, such as those related to vasculitides, motor involvement predominates over sensory abnormality and a multifocal onset is commonly observed. As has often been emphasized [4], the clinical picture in diabetic neuropathy is frequently complex and, particularly in the older diabetic subjects, may suggest the superimposition of focal peripheral nerve lesions onto a symmetric distal sensory and autonomic polyneuropathy. It is likely, on the evidence currently available, that both a metabolic insult to nerve particularly affecting sensory and autonomic function, and focal vascular lesions, are involved. This is supported by the observations of Sima et al. [32] who found that focal nerve fibre loss was evident in nerve biopsies from older patients with non-insulin-dependent diabetes but not in younger patients with insulin-dependent diabetes.

Acknowledgements. Financial support from the British Diabetic Association is gratefully acknowledged. The electron microscope was supplied by the Medical Research Council and the image analysis equipment was purchased with grants from the Stanley Thomas Johnson Foundation, Ciba-Geigy Ltd, Basel, the National Fund for Research into Crippling Diseases and the London University Central Research Fund. We also wish to thank J. M. Workman for technical help, Ms. K. Price for secretarial assistance and Mr. O.Fernando for his cooperation in obtaining the organ donor nerve biopsies.

\section{References}

1. Asbury AK, Aldredge H, Hershberg R, Fisher CM (1970) Oculomotor palsy in diabetes mellitus: a clinicopathological study. Brain 93:555-566

2. Pryce TD (1893) On diabetic neuritis, with a clinical and pathological description of three cases of diabetic pseudo-tabes. Brain 16: 416-424

3. Woltman HW, Wilder RM (1929) Diabetes mellitus: pathological changes in the spinal cord and peripheral nerves. Arch Int Med 44: 576-603

4. Thomas PK, Eliasson SG (1981) Diabetic neuropathy. In: Dyck PJ, Thomas PK, Lambert EH, Bunge R (eds) Peripheral neuropathy, 2nd edn. Saunders, Philadelphia, pp 1773-1810

5. Low PA, Tuck RR, Dyck PJ, Schmelzer JD, Yao JK (1984) Prevention of some electrophysiologic and biochemical abnor- 
malities with oxygen supplementation in experimental diabetic neuropathy. Proc Natl Acad Sci USA 81: 6894-6898

6. Tuck RR, Schmelzer JD, Low PA (1984) Endoneurial blood flow and oxygen tension in the sciatic nerve of rats with experimental diabetic neuropathy. Brain 107: 935-950

7. Dyck PJ, Hansen S, Karnes J, O'Brien P, Yasuda H, Windebank A, Zimmerman B (1985) Capillary number and percentage closed in human diabetic sural nerve. Proc Natl Acad Sci USA 82: 2513-2517

8. Dyck PJ, Karnes JL, O'Brien P, Okazaki H, Lais A, Engelstad J (1986) The spatial distribution of fiber loss in diabetic polyneuropathy suggests ischemia. Ann Neurol 19:440-449

9. Dyck PJ, Lais A, Karnes JL, O'Brien P, Rizza R (1986) Fiber loss is primary and multifocal in sural nerves in diabetic polyneuropathy. Ann Neurol 19: 425-439

10. Johnson PC, Doll SC, Cromer DW (1986) Pathogenesis of diabetic neuropathy. Ann Neurol 19:450-457

11. Korthals JK, Gieron MA, Dyck PJ (1988) Intima of epineurial arterioles is increased in diabetic polyneuropathy. Neurology (Cleveland) 38: 1582-1586

12. Malik RA. Newrick PG, Sharma AK, Jennings A, Ah-See AK, Mayhew TM, Jakubowski J, Boulton AJM, Ward JD (1989) Microangiopathy in human diabetic neuropathy: relationship between capillary abnormalities and the severity of neuropathy. Diabetologia 32: 92-102

13. Newrick PG, Wilson AJ, Jakubowski J, Boulton AJ, Ward JD (1986) Sural nerve oxygen tension in diabetes. Br Med J 293: 1053-1054

14. Powell HC, Rosoff J, Myers RR (1985) Microangiopathy in human diabetic neuropathy. Acta Neuropathol (Berl) 68: 295-305

15. Sugimura K, Dyck PJ (1982) Multifocal fiber loss in proximal sciatic nerve in symmetric distal diabetic neuropathy. $J$ Neurol Sci 53:501-509

16. Yasuda H, Dyck PJ (1987) Abnormalities of endoneurial microvessels and sural nerve pathology in diabetic neuropathy. Neurology (Cleveland) 37: 20-28

17. Harding AE, Thomas PK (1980) The clinical features of hereditary motor and sensory neuropathy, types 1 and 2. Brain 103: 259-280

18. Baur PS, Stacey TR (1977) The use of PIPES buffer in the fixation of mammalian and marine tissues for electron microscopy. $J$ Microsc 109: 315-327

19. Bell MA, Weddell AGM (1984) A morphometric study of intrafascicular vessels in mammalian sciatic nerve. Muscle Nerve 7: 524-534

20. Sievers J (1971) Basic two-dye stains for epoxy-embedded 0.3-1 um sections. Stain Technol 46: 195-199

21. Fagerberg SE (1959) Diabetic neuropathy: a clinical and histological study on the significance of vascular affections. Acta Med Scand 164 [Suppl 345]: 1-80
22. Bischoff A (1967) Die Ultrastruktur peripherer Nerven bei der diabetischen Neuropathie. Verh Dtsch Ges Inn Med 72: 1138-1141

23. Dolman CL (1963) The morbid anatomy of diabetic neuropathy. Neurology (Minneap) 13:135-142

24. Harriman D (1962) Ischaemic factor in diabetic neuropathy. In: 4th Internat Cong Neuropathol 3. Thieme, Stuttgart, p 164

25. Llewelyn JG, Thomas PK, Gilbey SG, Watkins PJ, Muddle JR (1988) Pattern of myelinated fibre loss in the sural nerve in neuropathy related to Type 1 (insulin-dependent) diabetes. Diabetologia 31: 162-167

26. Timperley WR, Boulton AJ, Davies-Jones GA, Jarratt JA, Ward JD (1985) Small vessel disease in progressive neuropathy associated with good metabolic control. J Clin Pathol 38: $1030-1038$

27. Behse F, Buchthal F, Carlsen F (1977) Nerve biopsy and nerve conduction studies in diabetic neuropathy. $\mathbf{J}$ Neurol Neurosurg Psychiatry 40: 1072-1082

28. Vital C, Le Blanc M, Vallat JM, Coquet M, Vallat M, Roques JC (1974) Etude ultrastructurale du nerf périphérique chez 16 diabétiques sans neuropathie clinique. Acta Neuropathol (Berl) 30: $63-72$

29. King RHM, Llewelyn JG, Thomas PK, Gilbey SG, Watkins PJ (1989) Diabetic neuropathy: abnormalities of Schwann cell and perineurial basal laminae. Implications for diabetic vasculopathy. Neuropathol Appl Neurobiol 15: 339-355

30. Gaylarde PM, Fonseca VA, Llewelyn G, Sarkany I, Thomas PK, Dandona P (1988) Transcutaneous oxygen tension in legs and feet of diabetic patients. Diabetes 37: 714-716

31. Flynn MD, Edmonds ME, Tooke JE, Watkins PJ (1988) Direct measurement of capillary blood flow in the diabetic neuropathic foot. Diabetologia 31: $652-656$

32. Sima AAF, Nathaniel V, Bril V, McEwen TAJ, Greene DA (1988) Histopathological heterogeneity of neuropathy in insulindependent and non-insulin-dependent diabetes, and demonstration of axo-glial dysjunction in human diabetic neuropathy. J Clin Invest 81: 349-364

Received: 27 December 1989

and in revised form: 26 April 1990

Prof. P.K. Thomas

Department of Neurological Science

Royal Free Hospital School of Medicine

Rowland Hill Street

London NW3 2PF

UK 